J. Dairy Sci. 98:8753-8763

http://dx.doi.org/10.3168/jds.2015-9760

(C) 2015, THE AUTHORS. Published by FASS and Elsevier Inc. on behalf

of the American Dairy Science Association ${ }^{\circledR}$. This is an open access article under

the CC BY-NC-ND license (http://creativecommons.org/licenses/by-nc-nd/3.0/).

\title{
Comparison of reproductive performance of primiparous dairy cattle following revaccination with either modified- live or killed multivalent viral vaccines in early lactation
}

\author{
P. H. Walz, ${ }^{* 1}$ T. Montgomery,† T. Passler,ł K. P. Riddell, ${ }^{*}$ T. D. Braden,§ Y. Zhang, ${ }^{*}$ P. K. Galik, ${ }^{*}$ and S. Zuidhof\# \\ *Department of Pathobiology, College of Veterinary Medicine, Auburn University, Auburn, AL 36849 \\ †Maple Row Dairy Farm, Saranac, Ml 48881 \\ ‡Department of Clinical Sciences, College of Veterinary Medicine, Auburn University, Auburn, AL 36849 \\ $\S$ Department of Anatomy, Physiology, and Pharmacology, College of Veterinary Medicine, Auburn University, Auburn, AL 36849 \\ \#Boehringer Ingelheim Vetmedica Inc., St. Joseph, MO 64506-2002
}

\begin{abstract}
The objective of this randomized clinical trial was to compare the effect of revaccination in primiparous dairy cows with modified live viral (MLV) or killed viral $(\mathrm{KV})$ vaccines containing bovine viral diarrhea virus (BVDV) and bovine herpesvirus-1 (BoHV-1) on (1) pregnancy rate following estrus synchronization-timed artificial insemination (TAI), (2) serum progesterone concentrations, and (3) serum neutralizing antibody titers at revaccination and at TAI. Primiparous dairy cows $(\mathrm{n}=692)$ that had been previously vaccinated with 4 doses of MLV vaccine as calves or heifers were randomized to receive either an MLV or a KV vaccine between 21 and $28 \mathrm{~d}$ in milk and $17 \mathrm{~d}$ before initiation of a double-Ovsynch-TAI protocol. Serum was collected within the double-Ovsynch protocol for determination of progesterone concentrations, and at vaccination and TAI for serum neutralizing antibody titers. Ultrasound pregnancy determinations were made at 30 and $60 \mathrm{~d}$ after TAI. No differences in pregnancy rates were observed between cows receiving MLV vaccine $(44 \%$; $\mathrm{n}=$ $326)$ or $\mathrm{KV}$ vaccine $(43 \% ; \mathrm{n}=336)$. No differences were observed in serum progesterone concentrations during a double-Ovsynch-TAI protocol between cows receiving MLV and KV vaccines. No differences were observed in BVDV 1 or BVDV 2 antibody titers at vaccination and TAI between cows receiving MLV or KV vaccine; however, BoHV-1 antibody titers were greater at TAI in cows receiving $\mathrm{KV}$ vaccine. Overall response to vaccination - defined as the percent of all individual cows that had any detectable increase in antibody titer from
\end{abstract}

Received April 28, 2015.

Accepted August 18, 2015.

${ }^{1}$ Corresponding author: walzpau@auburn.edu vaccination to TAI - was 39\% for BVDV 1, $45 \%$ for BVDV 2, and $61 \%$ for BoHV-1. In this research, use of an MLV vaccine did not impede reproduction when revaccination was performed between 21 and 28 DIM and just before enrollment in an estrus synchronization-TAI program in primiparous dairy cows; however, response to vaccination as defined by increases in virus-specific antibody titers could be considered less than ideal for this population of cattle.

Key words: immunity, vaccination, modified-live viral, killed viral

\section{INTRODUCTION}

Dairy herd profitability is predicated on reproductive performance because pregnancy and parturition initiate and renew lactation cycles. Reproductive efficiency of dairy herds is greatly affected by pregnancy losses due to infectious disease. Bovine viral diarrhea virus (BVDV) and bovine herpesvirus-1 (BoHV-1) are important viral pathogens of the bovine reproductive tract, resulting in infertility, abortions, and birth of calves with poor health (Walz et al., 2010; Givens et al., 2012). These pathogens and their respective diseases are present in dairy herds worldwide, thus affecting reproductive and overall efficiency of the dairy industry. Vaccination provides an important contribution to limiting reproductive losses associated with these viral infections and is an important control procedure to limit transmission of BVDV and BoHV-1 among dairy cattle populations. Modified-live viral (MLV) or killed viral $(\mathbf{K V})$ vaccines are available for BVDV and BoHV-1, often in multivalent formulations. Although MLV vaccines containing BVDV and BoHV-1 are considered to provide longer immunity and greater protection against reproductive loss (Rodning et al., 2010; Givens et al., 2012), concerns have been expressed regarding the safe- 
ty of these multivalent vaccines on female reproduction, with the majority of concern focused on the BoHV-1 fractions of the MLV vaccines causing abortions when given to pregnant cattle (O'Toole et al., 2012, 2014). An additional safety concern associated with MLV vaccines containing BVDV and BoHV-1 is infertility when MLV vaccines are administered in proximity to time of breeding (Van der Maaten and Miller, 1985; Chiang et al., 1990; Smith et al., 1990; Perry et al., 2013). Use of MLV vaccines in naïve heifers at the onset of standing estrus has been demonstrated to have negative effects on function of the corpus luteum (Van der Maaten and Miller, 1985; Smith et al., 1990). Furthermore, timing of a BoHV-1 viremia within the stage of the estrous cycle is a critical determinant of negative effects on estrous cyclicity and fertility. When BoHV-1 viremia occurs as a result of MLV vaccination during development of the corpus luteum after ovulation, severe necrotizing lesions develop (Van der Maaten et al., 1985; Miller and Van der Maaten, 1986). Severe necrotizing lesions within the corpus luteum have been associated with decreased circulating concentrations of progesterone (P4), prolonged interestrus intervals, and a subsequent, transient subfertility.

Efficient reproduction is important for optimal profitability on dairy cattle farms (Wiltbank et al., 2011). Many dairy farms do not attain optimal reproduction because of numerous factors related to management, health, and physiology of the lactating dairy cow. To circumvent some of the management problems, estrus synchronization programs have become standard components in the current breeding management of cows on most dairy operations (Macmillan, 2010). Many synchronization programs are based on protocols that allow timed inseminations (TAI) to bypass practical difficulties associated with estrus detection. Almost all programs involve strategically timed injections of $\mathrm{PGF}_{2 \alpha}$ and GnRH. While dairies are managing reproduction, attention must also be given to immunization against reproductive pathogens including BVDV and BoHV-1. Many large dairy operations utilize MLV vaccination against reproductive pathogens during the early postpartum period, and these vaccine administrations often occur within 2 to 4 wk of initiating estrus synchronization and TAI protocols. Because of the concerns associated with MLV vaccine usage on dairy cow reproductive performance, the overall goal of this study was to examine MLV vaccination in primiparous dairy cows where vaccination and initiation of an estrus synchronization-TAI program occurred in close time proximity. The null hypothesis was that MLV revaccination within $28 \mathrm{~d}$ of the initiation of a double-Ovsynch protocol would not result in transient subfertility and affect response to synchronization and pregnancy rate at TAI. Thus, the objective of this research was to compare the effect of revaccination in postpartum primiparous dairy cows at 21 to $28 \mathrm{~d}$ after calving with MLV or KV vaccination on (1) pregnancy rate, (2) serum $\mathrm{P} 4$ concentrations at 3 critical times during a double-Ovsynch/TAI protocol, and (3) serum neutralizing antibody titers at vaccination and at TAI.

\section{MATERIALS AND METHODS}

\section{Animals}

Six hundred ninety-two primiparous cows were used for the current study. The study was conducted on a large commercial dairy farm (3,300 lactating dairy cows) located in Saranac, Michigan, between August 2013 and February 2014. All primiparous cows were housed in freestall barns separate from multiparous cows, milked 3 times daily, provided ad libitum access to water, and fed twice daily a TMR that was balanced to meet or exceed nutrient recommendations for primiparous lactating dairy cows. All study procedures were approved by the Auburn University Animal Care and Use Committee (PRN 2013-2274) and the Auburn University Clinical Research Review Committee. All primiparous cows enrolled in this study had received 3 MLV (Express FP 10, Boehringer Ingelheim Vetmedica Inc., St. Joseph, MO) vaccinations as young calves at the farm of origin (at $5 \mathrm{wk}$ of age, at 3-4 mo of age, and at 6-7 mo of age), and 1 MLV (Express FP 10, Boehringer Ingelheim Vetmedica Inc.) vaccination while at a commercial heifer breeding facility in Garden City, Kansas, at approximately 2 mo before calving. Prepartum heifers were transported from the heifer breeding facility to the dairy at approximately 2 mo before the calving date. Following calving, only primiparous cows were enrolled that did not possess any of the following exclusion criteria: (a) BCS of 1 or 5, (b) history of retained fetal membranes, (c) treatment for uterine infections within the first 14 DIM, or (d) surgical correction of a displaced abomasum within first 14 DIM. Lists of eligible cows between 14 and 21 DIM were sent electronically every week to Auburn University for randomization to study group and for blood sampling. Enrollment dates for study cows occurred from June 24, 2013, to January 28, 2014. Eligible cows were randomly assigned to group A or group B using random number generator function of commercially available software (Excel, Microsoft Corp., Redmond, WA). Random numbers were generated for each cow and sorted from low to high. For each enrollment date, the lowest half of random numbers were assigned to group A and the highest half of random numbers were assigned to group B. Once cows were assigned to a treatment 


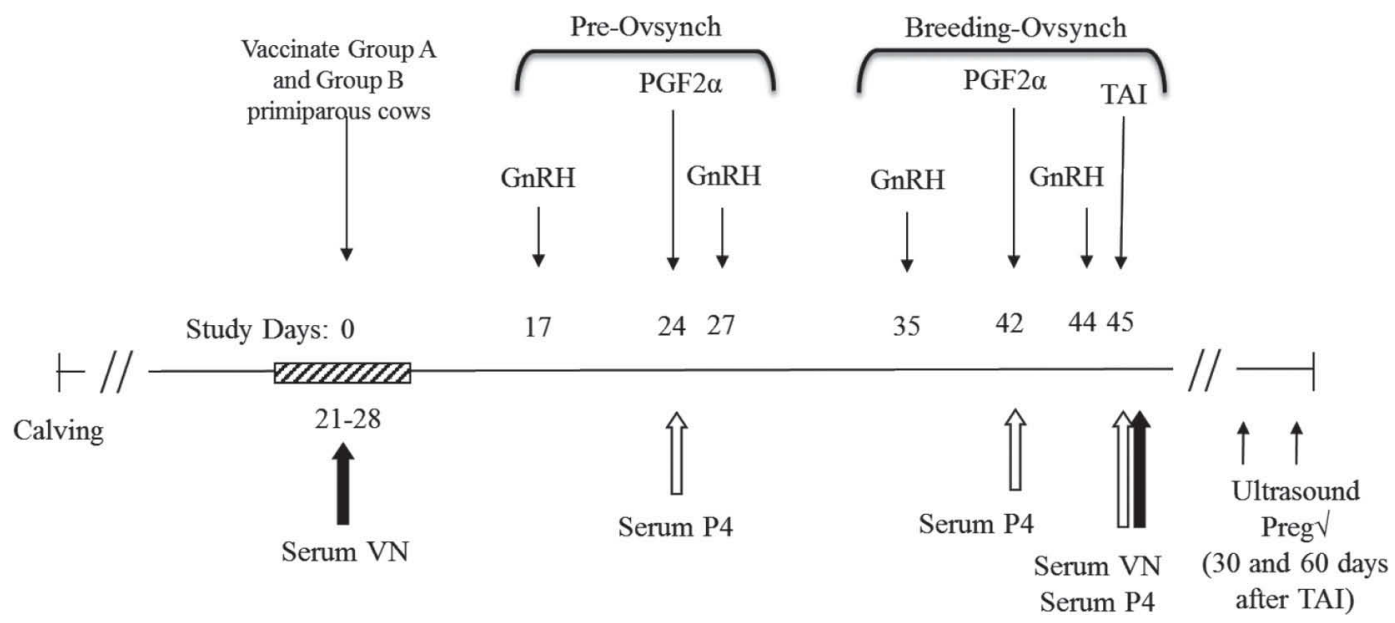

Figure 1. Study design and sample collection strategy. All primiparous cows were randomly assigned to group A or B and vaccinated according to group designation between 21 and 28 DIM. Group A cows received a multivalent modified-live viral vaccine (Express FP 10, Boehringer Ingelheim Vetmedica Inc., St. Joseph, MO), whereas group B cows received a multivalent killed viral vaccine (Triangle 10, Boehringer Ingelheim Vetmedica Inc.). Blood was collected from a randomly selected subset of cows from each group for determination of progesterone concentrations and antibody titers by serum virus neutralization. Sampling arrows are approximate DIM. TAI = timed AI; VN = virus neutralization assay; $\mathrm{P} 4=$ progesterone.

group, the random number generator function was again used to generate the subset of cows within each group for blood sampling at vaccination and during the estrus synchronization-TAI program. Equal numbers of cows within each group at each enrollment date were randomly assigned for blood sampling.

\section{Study Design and Sampling}

This was a randomized clinical trial (Figure 1). Between 21 and 28 DIM, all cows were vaccinated according to group assignment. At the time of vaccination, which corresponded to study d 0 , a blood sample was collected from the subset of cows randomly selected for blood sampling within each group. This initial blood sample was tested for neutralizing antibody concentrations to BVDV 1, BVDV 2, and BoHV-1. As part of farm protocol, all primiparous cows were subjected to an estrus synchronization-TAI protocol (Souza et al., 2008), with TAI occurring by 70 DIM. On d 17 (at approximately $40 \mathrm{DIM}$ ), all cows began the estrus synchronization-TAI program by receiving $100 \mu \mathrm{g}$ of GnRH (Fertagyl; Merck Animal Health, Millsboro, DE). On study d 24, blood was again collected on the subset of cows randomly selected for blood sampling within each group, and this blood sample coincided with the first $\mathrm{PGF}_{2 \alpha}(500 \mu \mathrm{g}$ of cloprostanol sodium, Estrumate; Merck Animal Health) administration as part of the pre-Ovsynch. On study d 42, another blood sample was collected from the subset of cows randomly selected for blood sampling. This sample was also processed for analysis of serum $\mathrm{P} 4$ concentrations, and this period coincided with the second $\mathrm{PGF}_{2 \alpha}$ administration as part of the breeding-Ovsynch. Finally, a fourth blood sample was collected at TAI, which occurred on study d 45. This blood sample was processed and tested for $\mathrm{P} 4$ concentrations and for serum neutralizing antibody titers to BVDV 1, BVDV 2, and BoHV-1. All cows were checked for pregnancy by ultrasound at approximately $30 \mathrm{~d}$ after TAI and again at $60 \mathrm{~d}$ after TAI. All cow records, including health records and pregnancy testing results were recorded using electronic record-keeping software (DairyComp 305, Valley Agricultural Software Inc., Tulare, CA).

\section{Vaccination}

Primiparous cows randomly assigned to group A were vaccinated with a commercially available MLV combination vaccine (Express FP 10, Boehringer Ingelheim Vetmedica Inc.). Cows randomly assigned to group B were vaccinated with a commercially available KV combination vaccine (Triangle 10, Boehringer Ingelheim Vetmedica Inc.). Vaccines were administered subcutaneously according to label directions. The commercially available MLV combination vaccine (Express FP 10) and the commercially available KV combination vaccine (Triangle 10) contained the following viral fractions: BoHV-1, BVDV type 1, BVDV type 2, bovine parainfluenza-3, and bovine respiratory syncytial virus, and the following bacterial fractions: Leptospira canicola, Leptospira grippotyphosa, Leptospira hardjo, Leptospira pomona, and Leptospira icterohemorrhagiae. 


\section{Serum P4}

Blood was collected from the randomly selected subset of cows and processed within $1 \mathrm{~h}$ of collection. Blood was centrifuged $(1,200 \times g$ for $30 \mathrm{~min})$ to obtain serum. Serum samples were frozen and subsequently analyzed for concentrations of P4. Progesterone concentrations were measured using an RIA kit (Coat-a-Count, Siemens Healthcare Diagnostics Inc., Los Angeles, CA) previously validated for bovine serum (Stevenson et al., 2012). Intra- and interassay coefficients of variation were both $<10 \%$. The sensitivity of this assay was 0.1 $\mathrm{ng} / \mathrm{mL}$.

\section{Virus Neutralization Assays}

The standard virus neutralization (VN) microtiter assay was used to detect serum antibodies directed against BVDV-1, BVDV-2, and BoHV-1 (Walz et al., 2008; Givens et al., 2012). Serum was collected for VN assays at vaccination and at TAI. The BVDV-1 cytopathic strain NADL, the BVDV-2 cytopathic strain $125 \mathrm{c}$, and the BoHV-1 Colorado strain were used as test viruses. Briefly, after heat inactivation at $56^{\circ} \mathrm{C}$ for $30 \mathrm{~min}$, serial 2-fold dilutions (1:2 to 1:4,096) of serum were made in $50 \mu \mathrm{L}$ of culture medium. For each dilution, 3 wells of a 96 -well polystyrene microtiter plate (Falcon tissue culture plates; Corning Life Sciences DL, Corning, NY) were inoculated with an equal volume $(50 \mu \mathrm{L})$ of culture medium containing a median tissue culture infective dose $\left(\right.$ TCID $\left._{50}\right)$ of the test strain of 100 to $500 / \mathrm{mL}$. After inoculation, the plate was incubated at $37^{\circ} \mathrm{C}$ in a humidified atmosphere of $5 \% \mathrm{CO}_{2}$ and air for $1 \mathrm{~h}$. Then, $2.5 \times 10^{3}$ Madin-Darby bovine kidney (MDBK) cells in $50 \mu \mathrm{L}$ of culture medium were added to each well. The plate was incubated for $72 \mathrm{~h}$ and evaluated visually for a cytopathic effect. Mean $\log _{2}$ antibody titers were calculated from the endpoint titers for the animals in each group.

\section{Statistical Analyses}

All statistical analyses were performed using commercially available statistical software (JMP and SAS 9.3, SAS Institute Inc., Cary, NC). Categorical data including outcome of AI (pregnant, open, or aborted) and response to vaccination (seroconversion or no response) were compared between groups using Fisher's Exact test. In addition, the pregnancy rate was compared with the response to vaccination within groups for primiparous cows that were randomly selected for blood sampling using Fisher's Exact test. Continuous data were evaluated for normality by visual inspection of histograms and normal quantile plots as well as by formal testing for departures from normality using the Shapiro-Wilk W-test. Variables that violated the assumption of normality included DIM at vaccination, DIM at start of pre-Ovsynch, DIM at TAI, and days between vaccination and TAI, which were analyzed using the nonparametric Wilcoxon test.

The response variables $\mathrm{P} 4$ concentration and antibody titers were measured repeatedly on the same experimental unit; therefore, data were analyzed using repeated-measures methodology using the following model: response $=$ group + time + group $\times$ time . Post hoc pairwise comparisons were performed using Tukey's honestly significant difference (HSD) test. Serum antibody titers against each virus evaluated were subjected to a logarithmic transformation to normalize the distribution of the data, which were subsequently analyzed by the use of multivariate repeated-measures ANOVA. For analysis, the reciprocal of serum antibody titers was $\log _{2}$-transformed, which were then back-transformed as geometric means for presentation of results. If differences between groups were detected over time, the geometric means of the reciprocal of the antibody titers were compared at each time point using an ANOVA F-test. Progesterone concentrations at various time points were compared using multivariate repeated-measures ANOVA. If differences among groups were detected over time, the results were compared at each time point using an ANOVA F-test.

\section{RESULTS}

A total of 692 cows were randomized into 2 equal group sizes for enrollment in this study, with 346 cows enrolled in group A (Express FP 10) and 346 enrolled in group B (Triangle 10). Four group A cows and 2 group B cows were disqualified from study between the time of randomization and the date of vaccination because of health issues, resulting in group sizes of 342 group A cows and 344 group B cows (total of 686 cows that were vaccinated; Table 1). Descriptive statistics were performed on group characteristics (Table 2), and no differences were observed between groups $\mathrm{A}$ and $\mathrm{B}$ for DIM at vaccination $(P=0.46)$, DIM at start of pre-Ovsynch $(P=0.28)$, DIM at TAI $(P=0.37)$, and number of days between vaccination and TAI $(P=$ $0.28)$. With respect to DIM at the time of vaccination, all 342 group A cows received MLV vaccine between 21 and 27 DIM, whereas 340 group B cows received KV vaccine between 21 and 27 DIM, and the remaining 4 cows received $\mathrm{KV}$ vaccine at $28 \mathrm{DIM}$; thus, all cows enrolled in this study were vaccinated between 21 and 28 DIM. The average days between vaccination and the first $\mathrm{GnRH}$ administration as part of the pre-Ovsynch protocol was $17.38 \mathrm{~d}$ (range: $6-60 \mathrm{~d}$ ) and $17.58 \mathrm{~d}$ (range: 
Table 1. Outcomes for project cows according to group allocation ${ }^{1}$

\begin{tabular}{lccccr}
\hline Group & $\begin{array}{c}\text { No. of cows randomly } \\
\text { selected for study }\end{array}$ & $\begin{array}{c}\text { No. of cows } \\
\text { initially excluded }\end{array}$ & $\begin{array}{c}\text { No. of } \\
\text { DNB cows }\end{array}$ & $\begin{array}{c}\text { No. of open } \\
\text { cows }^{4}\end{array}$ & $\begin{array}{c}\text { No. of } \\
\text { pregnant cows }^{5}\end{array}$ \\
\hline Group A & 346 & 4 & 16 & 175 & 142 \\
Group B & 346 & 2 & 8 & 173 & 140 \\
\hline
\end{tabular}

${ }^{1}$ Group A cows received a multivalent modified-live viral vaccine (Express FP 10, Boehringer Ingelheim Vetmedica Inc., St. Joseph, MO), whereas group B cows received a multivalent killed viral vaccine (Triangle 10, Boehringer Ingelheim Vetmedica Inc.). Of the 692 cows selected for study, 326 group A and 336 group B cows were inseminated. Breeding results at timed AI were determined by ultrasound pregnancy check at 30 and $60 \mathrm{~d}$ after insemination.

${ }^{2}$ Cows that were excluded after randomization but before vaccination.

${ }^{3}$ Cows vaccinated but not inseminated (DNB = did not breed; e.g., sold, died, uterine adhesions, temperament).

${ }^{4}$ Cows not pregnant at $30-\mathrm{d}$ ultrasound pregnancy check.

${ }^{5}$ Cows confirmed pregnant at 30-d and 60-d ultrasound pregnancy check.

${ }^{6}$ Cows confirmed pregnant at 30 -d but were not pregnant at 60 -d ultrasound pregnancy check.

8-48 d) for groups A and B, respectively. In group A, 286 of the 342 cows vaccinated $(84 \%)$ were given their vaccine exactly $17 \mathrm{~d}$ before the first $\mathrm{GnRH}$ administration as part of the pre-Ovsynch protocol. In group B, 296 of the 344 cows $(86 \%)$ were given their vaccine exactly $17 \mathrm{~d}$ before the first GnRH administration as part of the pre-Ovsynch protocol.

Of the 342 group A cows administered MLV vaccine, insemination at TAI was performed in 326 cows (95\%). Of the 344 group B cows administered KV vaccine, insemination at TAI was performed in 336 cows $(98 \%)$. Reasons for cows to be enrolled but not inseminated (total $\mathrm{n}=24$; Table 1 ) included sold-lame $(\mathrm{n}=6)$, sold-poor production $(\mathrm{n}=2)$, sold-leg injury $(\mathrm{n}=1)$, sold-pneumonia $(\mathrm{n}=2)$, sold-mastitis $(\mathrm{n}=$ $1)$, sold-undetermined $(\mathrm{n}=1)$, sold-listeria $(\mathrm{n}=1)$, died-pneumonia $(\mathrm{n}=1)$, do not breed (DNB)-kicker $(\mathrm{n}=2)$, DNB-poor production $(\mathrm{n}=2)$, DNB-uterine adhesions $(\mathrm{n}=1)$, bred late $(\mathrm{n}=2)$, pyometra $(\mathrm{n}=1)$, and hospital mastitis $(\mathrm{n}=1)$.

Of the 686 study cows that received vaccine, 226 cows ( $\mathrm{n}=111$ for group $\mathrm{A} ; \mathrm{n}=115$ for group $\mathrm{B}$ ) were selected for blood sampling. Complete blood samples (vaccination, 1st $\mathrm{PGF}_{2 \alpha}$, 2nd $\mathrm{PGF}_{2 \alpha}$, and $\mathrm{TAI}$ ) were available for 88 group A cows $(79 \%)$ and 91 group B cows $(79 \%)$.

\section{Pregnancy Rate}

Overall pregnancy rate was $43 \%$ for enrolled cows, with pregnancy rates of $44 \%$ and $43 \%$ for group A and group B cows, respectively (Table 2). This pregnancy rate is defined as the cows detected pregnant at the 30-d ultrasound pregnancy check and confirmed pregnant at the 60-d ultrasound pregnancy check. For the cows that were inseminated, 9 group A cows and 19 group B cows were determined to be pregnant at the 30-d ultrasound pregnancy check but then diagnosed as open at the 60-d pregnancy check. The causes of fetal loss after d 30 and before d 60 of gestation were undetermined. No significant differences in pregnancy rate and abortion rate were detected between group A and group B cows (Table 2).

\section{Serum P4}

Serum P4 concentrations were evaluated on the subset of cows randomly selected for bleeding. Complete sets of samples for $\mathrm{P} 4$ analysis (1st $\mathrm{PGF}_{2 \alpha}, 2$ nd $\mathrm{PGF}_{2 \alpha}$, and TAI) were available for 88 group A cows (79\%) and 91 group B cows (79\%). Individual samples from group A and group B cows were available for testing, with a final sample size of 95, 104, and 103 for group A cows

Table 2. Descriptive statistics for average DIM at vaccination, average DIM at timed AI (TAI), average days between vaccination and TAI, and statistical comparisons between groups ${ }^{1}$ on primary outcome measurements of pregnancy rate and abort rate

\begin{tabular}{lccccc}
\hline Group & $\begin{array}{c}\text { DIM at vaccination } \\
(\text { mean } \pm \text { SEM) }\end{array}$ & $\begin{array}{c}\text { DIM at TAI } \\
(\text { mean } \pm \text { SEM })\end{array}$ & $\begin{array}{c}\text { Days between } \\
\text { vaccination and TAI }\end{array}$ & $\begin{array}{c}\text { Pregnancy } \\
\text { rate }^{2}(\%)\end{array}$ \\
\hline Group A & $24.02 \pm 0.11$ & $68.41 \pm 0.23$ & $44.38 \pm 0.24$ & 43.6 \\
Group B & $23.89 \pm 0.10$ & $68.47 \pm 0.19$ & $44.58 \pm 0.18$ & 42.9 \\
$P$-value & 0.46 & 0.37 & 0.28 & 0.94 \\
rate $^{3}(\%)$
\end{tabular}

${ }^{1}$ Group A cows received a multivalent modified-live viral vaccine (Express FP 10, Boehringer Ingelheim Vetmedica Inc., St. Joseph, MO), whereas group B cows received a multivalent killed viral vaccine (Triangle 10, Boehringer Ingelheim Vetmedica Inc.).

${ }^{2}$ Pregnancy rate is defined as percent of eligible cows that became pregnant.

${ }^{3}$ Abortion rate is defined as percent of cows confirmed pregnant at 30-d ultrasound pregnancy check that were found not pregnant at $60-\mathrm{d}$ ultrasound pregnancy check. 
at 1st $\mathrm{PGF}_{2 \alpha}$, 2nd $\mathrm{PGF}_{2 \alpha}$, and TAI, respectively, and a final sample size of 99, 102, and 103 for Group B cows at 1st $\mathrm{PGF}_{2 \alpha}$, 2nd $\mathrm{PG}_{\mathrm{F} 2 \alpha}$, and TAI, respectively. The mean serum $\mathrm{P} 4$ concentrations were lower at 1 st $\mathrm{PGF}_{2 \alpha}$ than at $2 \mathrm{nd} \mathrm{PGF}_{2 \alpha}$. The mean serum $\mathrm{P} 4$ concentration was lowest at TAI. No significant differences were noted in serum $\mathrm{P} 4$ concentrations at any time point between groups (Figure 2).

\section{BVDV- and BoHV-1-Specific Antibody Determinations by Virus Neutralization}

Antibody titers were determined at vaccination and at TAI for 104 group A cows and 104 group B cows. At the time of vaccination, all cows possessed neutralizing antibody titers to BVDV 1 and BVDV 2, except 1 group $B$ cow that was seronegative to BVDV 1 and BVDV 2 at vaccination. With respect to the magnitude of BVDV antibody titers at the time of vaccination, all cows had BVDV 1 and BVDV 2 titers >16, except for 4 group A cows and 6 group B cows that had antibody titers to BVDV 2 of $<16$. In addition, all cows except for 8 group A cows and 9 group B cows had BVDV 1 antibody titers $\leq 1,024$. For the BoHV-1 antibody titers, all project cows had neutralizing titers except 5 group A cows and 6 group B cows, which were seronegative to BoHV-1 at the time of vaccination.

The geometric mean antibody titer increased in group A and group B cows between vaccination and TAI, which was approximately $45 \mathrm{~d}$ after vaccination (Table 3). No significant differences in antibody titers were detected between group A and group B cows with respect to BVDV 1 and BVDV 2 neutralizing antibody titers at vaccination or at TAI; however, a significantly higher BoHV-1 antibody titer was present at TAI in group B cows compared with group A cows.

The neutralizing antibody titers between samples taken at vaccination and samples taken at TAI were also evaluated for each individual cow to determine an individual cow's response to vaccination (Figure 3). To determine the response to vaccination, we calculated the difference between the $\log _{2}$ titer at vaccination and

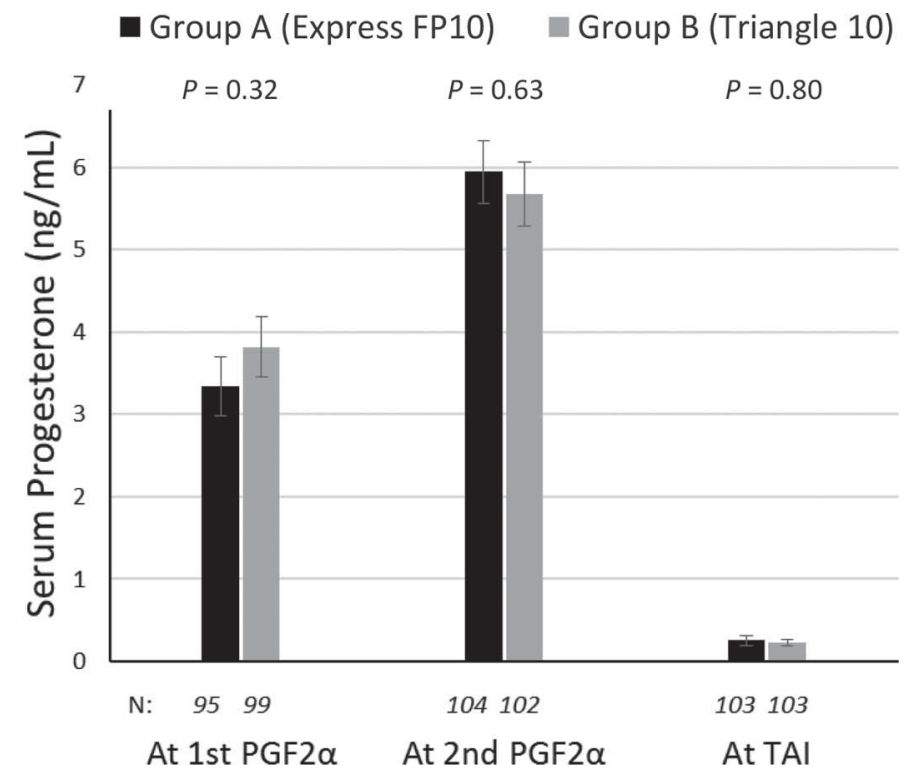

Figure 2. Serum progesterone concentrations (mean \pm SEM). Samples for progesterone analysis were obtained at the first and second prostaglandin $\left(\mathrm{PGF}_{2 \alpha}\right)$ administration and at timed $\mathrm{AI}(\mathrm{TAI}) . \mathrm{n}=$ no. of cows in each group available for testing at each sampling point. No significant differences in progesterone concentrations were detected between groups at any time point. Express FP10 and Triangle 10 from Boehringer Ingelheim Vetmedica Inc., St. Joseph, Missouri.

at TAI. For example, a titer of $16\left(\log _{2}=4\right)$ at vaccination and a titer of $64\left(\log _{2}=6\right)$ at TAI would have a calculated difference of 2 . Furthermore, a positive response to vaccination was defined as a difference between the $\log _{2}$ titer at vaccination and TAI $\geq 1$. A nonresponse to vaccination was defined as a difference between the $\log _{2}$ titer at vaccination and TAI of $\leq 0$. Overall response to vaccination-defined as the percent of all individual cows that had any detectable increase in antibody titer from vaccination to TAI-was $39 \%$ for BVDV 1, $45 \%$ for BVDV 2, and $61 \%$ for BoHV1 (Table 4). When responses were compared between group A and group B cows, no significant differences were noted for BVDV 1 and BVDV 2 response to vaccination; however, there was a significantly increased percentage of group B cows that responded to vacci-

Table 3. Geometric mean serum neutralizing antibody titers against bovine viral diarrhea virus (BVDV; NADL strain) 1, BVDV 2 (strain 125C), and bovine herpesvirus-1 (BoHV-1; Colorado strain)

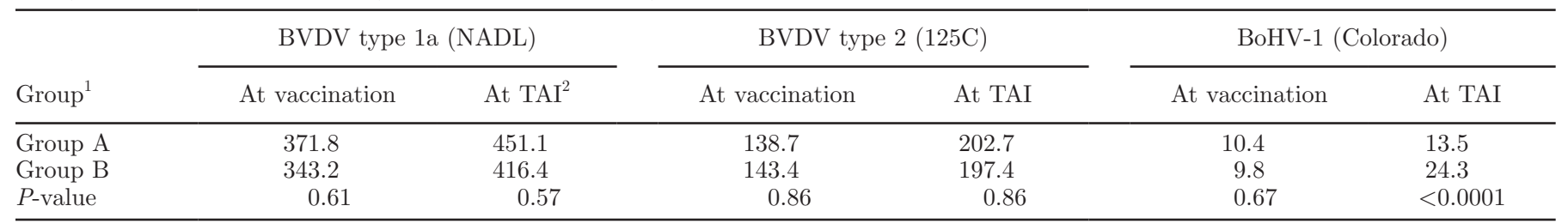

${ }^{1}$ Group A cows received a multivalent modified-live viral vaccine (Express FP 10, Boehringer Ingelheim Vetmedica Inc., St. Joseph, MO), whereas group B cows received a multivalent killed viral vaccine (Triangle 10, Boehringer Ingelheim Vetmedica Inc.).

${ }^{2} \mathrm{TAI}=$ timed $\mathrm{AI}$. 


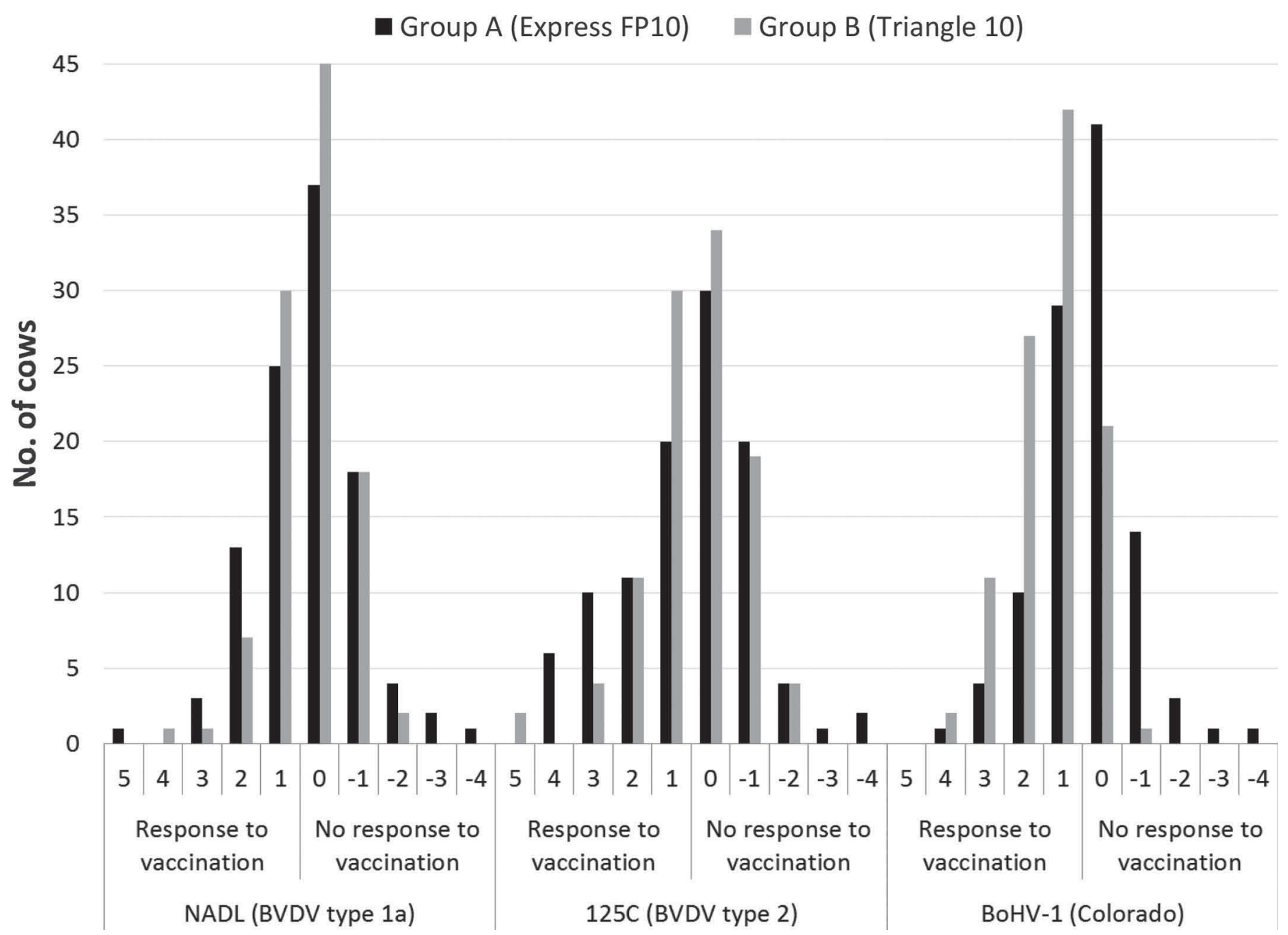

Figure 3. Number of cows categorized by magnitude of response to vaccination according to group allocation and bovine viral diarrhea virus (BVDV) 1, BVDV 2, or bovine herpesvirus-1 (BoHV-1) antibodies. Individual cow responses to vaccination were calculated based upon the log 2 titer difference between samples taken at vaccination and at timed AI (TAI). A response to vaccination was defined as a 1-fold to 5-fold increase in $\log _{2}$ titer. No response to vaccination was defined as a stable (0) or 1-fold to 4 -fold decrease in $\log _{2}$ titer. Express FP10 and Triangle 10 from Boehringer Ingelheim Vetmedica Inc., St. Joseph, Missouri.

nation based upon BoHV-1 antibody titers compared with group A cows (Table 3). In primiparous cows that were seronegative to $\mathrm{BoHV}-1$ at vaccination (group A: $\mathrm{n}=5$; group $\mathrm{B}: \mathrm{n}=6$ ), all had a positive response to vaccination. For the single group B cow that was seronegative to BVDV 1 and BVDV 2 at vaccination, the titers to each virus had increased at TAI. For the cows that had BVDV 2 titers $<16$ at vaccination (group A: $\mathrm{n}=4$; group $\mathrm{B}: \mathrm{n}=6$ ), all cows had 2-fold or greater increases in BVDV 2 antibody titer with the exception of 1 group B cow, in which a single-fold increase in titer was observed. Pregnancy rates were also evaluated in primiparous cows that were randomly selected for antibody determination, and a comparison was made between cows that had a positive response versus cows that had no response to vaccination. No significant differences were observed when comparing pregnancy rates within group A and group B between primiparous cows that had a positive response to vaccination and primiparous cows that had no response to vaccination (data not shown).

\section{DISCUSSION}

The primary objective of this research was to evaluate reproductive safety associated with administration of MLV vaccines containing BVDV and BoHV-1 fractions on subsequent fertility of dairy cattle when vaccination and initiation of an estrus synchronization program occur close in time within the first $60 \mathrm{~d}$ postpartum. Administration of an MLV vaccine containing BVDV or BoHV-1 at less than $28 \mathrm{~d}$ before breeding is considered 
pregnancy rate. The effect of energy status during the transition period - from $3 \mathrm{wk}$ before to $3 \mathrm{wk}$ after calving - on reproductive efficiency in dairy cattle has been demonstrated in multiple studies (Ospina et al., 2010; Garverick et al., 2013; Carvalho et al., 2014). Body condition at TAI and loss of body condition between parturition and $21 \mathrm{~d}$ postpartum have a major effect on pregnancy per AI. Pregnancy per AI for primiparous cows that lost condition from parturition to 21 DIM at the 40 -d pregnancy check was only $30.8 \%$ compared with 46.9 and $85.8 \%$ for primiparous cows that maintained or gained condition, respectively (Carvalho et al., 2014). An attempt was made to limit the influence of poor body condition on fertility in the present study by excluding all heifers with a BCS of 1 ; however, determining loss of body condition between parturition and vaccination and determining body condition at TAI could have provided more useful information on the influence of body condition on pregnancy rate, and potentially on antibody responses to vaccination.

When designing this experiment, we decided to use $\mathrm{KV}$ vaccine as the control group treatment rather than including a group of primiparous cows that remained unvaccinated. Although including an unvaccinated control group in the study design would have been optimal to evaluate the effect of vaccination in general on dairy cow fertility, the risk of reproductive problems associated with infection with field strains of BVDV or BoHV-1 was considered too high to leave a population of cows unvaccinated. Exposure to field strains of BVDV or BoHV-1 before enrollment in or during the study cannot be definitively excluded. At the time of vaccination, the majority of study animals had serum viral neutralizing antibody titers to BVDV and BoHV-1, likely the result of vaccination as young calves and vaccination within $60 \mathrm{~d}$ before calving. Although exposure to field strains of BVDV and BoHV-1 could have occurred before the study, presence of serum neutralizing antibody titers $<1,024$ in $>90 \%$ of the study cattle makes exposure to field strains less likely.

Although the primary purpose of this study was to evaluate safety; that is, the effect of MLV vaccination on subsequent fertility, a secondary objective was to evaluate serological responses in dairy cattle when MLV vaccines were administered during the first month following calving. Antibody responses are often referred to as a surrogate or secondary assessment for vaccine efficacy in the face of a live viral challenge; however, serologic responses can be a useful proxy for vaccine response and to determine whether an animal is properly immunized (Dubovi, 2013). Following vaccination, MLV- and KV-vaccinated groups of cows exhibited an elevation in the geometric mean antibody titers, similar to a previous report when multiparous and primiparous dairy cattle were administered MLV or KV vaccines at 35 DIM (Dubovi et al., 2000). In contrast to the previous report where MLV-vaccinated cattle developed a significantly greater antibody titer against BVDV and BoHV-1 compared with KV-vaccinated cattle (Dubovi et al., 2000), we observed no significant differences between MLV- and KV-vaccinated cattle in antibody titers to BVDV at TAI ( $45 \mathrm{~d}$ following vaccination) but did observe a significantly higher BoHV-1 antibody titer in the KV-vaccinated cattle. The significant elevation in BoHV-1 antibody titers but not BVDV antibody titers following $\mathrm{KV}$ vaccination is an interesting observation in the present study and warrants further investigation. In beef calves, a significant increase in antibody titer to BVDV 1, BVDV 2, and BoHV-1 was observed when a commercially available $\mathrm{KV}$ vaccine was used to booster 11-mo-old calves that had been previously administered 2 doses of a commercially available MLV at 1 to $2 \mathrm{mo}$ and again at $5.5 \mathrm{mo}$ of age (Royan, 2009). In another study, beef calves administered different priming and boosting strategies using MLV and KV vaccines demonstrated similar antibody responses in calves administered MLV-MLV and MLVKV prime-boost strategies (Grooms and Coe, 2002). In these studies, elevations in antibody responses to both BVDV and BoHV-1 were observed; in contrast, we observed elevations only to BoHV-1 and not BVDV in the present study. Differences in BVDV vaccine strains in the MLV priming and KV boosting vaccines in the present study and differences in immune responsiveness to BVDV and BoHV-1 in the early lactation period might explain this difference in antibody responses.

Although antibody titers cannot be compared across studies because of differences in animal populations being tested, cell lines and test strains used in the assay, and so on, the magnitude of the response in the present study was lower than in a previous report evaluating vaccine responses in lactating dairy cattle (Dubovi et al., 2000). Primiparous cattle in the present study had received 4 doses of MLV vaccine before first parturition. As a result, the antibody titer at vaccination was much higher in our study compared with that in the previous report (Dubovi et al., 2000), and this higher level of humoral immunity could limit replication of the MLV vaccine. The timing of vaccination was different as well. In the present study, all cattle were vaccinated between 21 and 28 DIM compared with the previous study, in which cattle were vaccinated at 35 DIM. As the transition period is thought to end around $3 \mathrm{wk}$ postpartum (Grummer, 1995), the timing of vaccination at 21 to 28 DIM is close to the end of the transition period. Although data support the high frequency of negative energy balance in dairy cattle and the subsequent effect on negative health events (mastitis, metri- 
tis), poor reproduction, and lower milk yield, no data are available on the effects of negative energy balance on vaccine responses when vaccination is performed in early lactation. The duration of time between vaccination and assessing the response to vaccination by measuring antibody titer also differed between our study and the previous study (Dubovi et al., 2000). In our study, $45 \mathrm{~d}$ elapsed between vaccination and assessing response to vaccination at TAI as opposed to 14 and 35 $\mathrm{d}$ in the previous report (Dubovi et al., 2000). As such, an increase and subsequent decline in the anamnestic antibody response over the course of $45 \mathrm{~d}$ might also affect the observed $<60 \%$ response to BVDV titers. In most studies, response to vaccination as determined by antibody titers is usually assessed between 21 and $28 \mathrm{~d}$ following vaccination. In the previous report, the antibody titers to BVDV did decline from $14 \mathrm{~d}$ after vaccination to $35 \mathrm{~d}$ after vaccination, albeit slightly (Dubovi et al., 2000).

Although the geometric mean antibody titers increased in MLV- and KV-vaccinated cattle in this study, the overall percentage of cows that developed a humoral immune response was low. Less than 50\% of cattle in either group had an elevation in antibody titer when samples were obtained $45 \mathrm{~d}$ after vaccination at TAI, with the exception of $\mathrm{KV}$-vaccinated animals against BoHV-1. Increases in antibody titers are often observed in naïve animals receiving a primary immunization. The cattle utilized in the present study were not naïve, having received 4 doses of MLV vaccine before vaccination at 21 to 28 DIM. Poor humoral immune responses in a high percent of individual cows following vaccination at 21 to 28 DIM raise questions concerning vaccination at this time and certainly merits further investigation. As stated previously, antibody titers are a proxy measurement for vaccine efficacy, where vaccination followed by challenge is considered a more appropriate assessment of vaccine efficacy (van Oirschot et al., 1999). Evaluation of vaccine efficacy by challenge experiments in dairy cattle vaccinated under this strategy is warranted. Delaying vaccination to 35 DIM or for several additional weeks could improve immune responsiveness; however, dairy producers are concerned about the effects of vaccination at this time on milk production and the effects of MLV vaccination on fertility when administered close to breeding. Milk production was not affected by MLV or KV vaccination at 35 DIM (Dubovi et al., 2000) or when MLV vaccine was administered between 21 and 31 DIM to primiparous dairy cows (Kleinhenz et al., 2014). Due to concerns associated with MLV safety, administration of an MLV vaccine containing BVDV or BoHV-1 at less than $28 \mathrm{~d}$ before breeding is considered an off-label use, irrespec- tive of immune status. Delaying vaccination beyond 28 DIM could push the administration to within the pre-Ovsynch portion of the synchronization or between the pre-Ovsynch and breeding-Ovsynch portions of the double-Ovsynch program. Use of MLV or KV vaccines before initiation of an estrus synchronization-TAI program in dairy cattle should continue to be evaluated, especially compared with this use in dairy cows not receiving vaccine at this time to thoroughly evaluate the effect of vaccination on fertility and milk production responses.

\section{CONCLUSIONS}

Balancing safety and efficacy of vaccinating cattle against viral reproductive pathogens is critically important to the profitability of dairy farms. In this research, use of MLV vaccine, compared with KV vaccine, did not impede reproduction when revaccination was performed between 21 and 28 DIM and $17 \mathrm{~d}$ before enrollment in an estrus synchronization-TAI program in primiparous dairy cows; however, response to vaccination as defined by increases in virus-specific antibody titers should be considered less than ideal for this population of cattle. The proportion of cows that had an increase in BVDV-specific antibody titers was less than $50 \%$ for both groups. This finding could indicate that use of vaccines directed against viral reproductive pathogens may not be as efficacious in this population due to the high energy demands and stress associated with the postpartum period in primiparous dairy cows.

\section{ACKNOWLEDGMENTS}

The authors thank the owner and staff of Maple Row Dairy LLC (Saranac, MI) for performance of the study. This study was funded by Boehringer Ingelheim Vetmedica Inc. (St. Joseph, MO).

\section{REFERENCES}

Bolton, M., D. Brister, B. Burdett, H. Newcomb, S. Nordstrom, B. Sanders, and T. Shelton. 2007. Reproductive safety of vaccination with Vista 5 L5 SQ near breeding time as determined by the effect on conception rates. Vet. Ther. 8:177-182.

Carvalho, P. D., A. H. Souza, M. C. Amundson, K. S. Hackbart, M. J. Fuenzalida, M. M. Herlihy, H. Ayres, A. R. Dresch, L. M. Vieira, J. N. Guenther, R. R. Grummer, P. M. Fricke, R. D. Shaver, and M. C. Wiltbank. 2014. Relationships between fertility and postpartum changes in body condition and body weight in lactating dairy cows. J. Dairy Sci. 97:3666-3683.

Chiang, B. C., P. C. Smith, K. E. Nusbaum, and D. A. Stringfellow. 1990. The effect of infectious bovine rhinotracheitis vaccine on reproductive efficiency in cattle vaccinated during estrus. Theriogenology 33:1113-1120.

Dubovi, E. J. 2013. Laboratory diagnosis of bovine viral diarrhea virus. Biologicals 41:8-13. 
Dubovi, E. J., Y. T. Grohn, M. A. Brunner, and J. A. Hertl. 2000. Response to modified live and killed multivalent viral vaccine in regularly vaccinated, fresh dairy cows. Vet. Ther. 1:49-58.

Garverick, H. A., M. N. Harris, R. Vogel-Bluel, J. D. Sampson, J. Bader, W. R. Lamberson, J. N. Spain, M. C. Lucy, and R. S. Youngquist. 2013. Concentrations of nonesterified fatty acids and glucose in blood of periparturient dairy cows are indicative of pregnancy success at first insemination. J. Dairy Sci. 96:181-188.

Givens, M. D., M. S. Marley, C. A. Jones, D. T. Ensley, P. K. Galik, Y. Zhang, K. P. Riddell, K. S. Joiner, B. W. Brodersen, and S. P. Rodning. 2012. Protective effects against abortion and fetal infection following exposure to bovine viral diarrhea virus and bovine herpesvirus 1 during pregnancy in beef heifers that received two doses of a multivalent modified-live virus vaccine prior to breeding. J. Am. Vet. Med. Assoc. 241:484-495.

Grooms, D. L., and P. Coe. 2002. Neutralizing antibody responses in preconditioned calves following vaccination for respiratory viruses. Vet. Ther. 3:119-127.

Grummer, R. R. 1995. Impact of changes in organic nutrient metabolism on feeding the transition dairy cow. J. Anim. Sci. 73:28202833.

Herlihy, M. M., J. O. Giordano, A. H. Souza, H. Ayres, R. M. Ferreira, A. Keskin, A. B. Nascimento, J. N. Guenther, J. M. Gaska, S. J. Kacuba, M. A. Crowe, S. T. Butler, and M. C. Wiltbank. 2012. Presynchronization with Double-Ovsynch improves fertility at first postpartum artificial insemination in lactating dairy cows. J. Dairy Sci. 95:7003-7014.

Kleinhenz, M. D., B. E. Miller, S. Zuidhof, and P. J. Gorden. 2014. Comparison of milk production changes in adult Holstein cows vaccinated with a 5 -way modified-live virus vaccine containing a Mannheimia haemolytica toxoid versus a 5-way modified-live virus vaccine containing a 5-way Leptospira bacterin. Bovine Pract. 48:139-142.

Macmillan, K. L. 2010. Recent advances in the synchronization of estrus and ovulation in dairy cows. J. Reprod. Dev. 56(Suppl.):S42S47.

Miller, J. M., and M. J. Van der Maaten. 1986. Experimentally induced infectious bovine rhinotracheitis virus infection during early pregnancy: Effect on the bovine corpus luteum and conceptus. Am. J. Vet. Res. 47:223-228.

O'Toole, D., C. C. Chase, M. M. Miller, and H. V. Campen. 2014. Kennedy, the early sixties, and visitation by the angel of death. Vet. Pathol. 51:1051-1062.

O'Toole, D., M. M. Miller, J. L. Cavender, and T. E. Cornish. 2012. Pathology in practice: Abortion in the heifers of this report was a result of BoHV-1 infection. J. Am. Vet. Med. Assoc. 241:189-191.

Ospina, P. A., D. V. Nydam, T. Stokol, and T. R. Overton. 2010. Association between the proportion of sampled transition cows with increased nonesterified fatty acids and beta-hydroxybutyrate and disease incidence, pregnancy rate, and milk production at the herd level. J. Dairy Sci. 93:3595-3601.

Perry, G. A., A. D. Zimmerman, R. F. Daly, R. E. Buterbaugh, J. Rhoades, D. Scholz, A. Harmon, and C. C. Chase. 2013. The ef- fects of vaccination on serum hormone concentrations and conception rates in synchronized naive beef heifers. Theriogenology 79:200-205.

Rodning, S. P., M. S. Marley, Y. Zhang, A. B. Eason, C. L. Nunley, P. H. Walz, K. P. Riddell, P. K. Galik, B. W. Brodersen, and M. D. Givens. 2010. Comparison of three commercial vaccines for preventing persistent infection with bovine viral diarrhea virus. Theriogenology 73:1154-1163.

Royan, G. 2009. Comparison of the BVDV, BHV-1, and BRSV anamnestic response to modified-live or inactivated vaccines in calves previously vaccinated with a modified-live virus vaccine. Bovine Pract. 43:44-50

Smith, P. C., K. E. Nusbaum, R. P. Kwapien, D. A. Stringfellow, and K. Driggers. 1990. Necrotic oophoritis in heifers vaccinated intravenously with infectious bovine rhinotracheitis virus vaccine during estrus. Am. J. Vet. Res. 51:969-972.

Souza, A. H., H. Ayres, R. M. Ferreira, and M. C. Wiltbank. 2008. A new presynchronization system (Double-Ovsynch) increases fertility at first postpartum timed AI in lactating dairy cows. Theriogenology 70:208-215.

Stevenson, J. S., S. L. Pulley, and H. I. Mellieon Jr. 2012. Prostaglandin F2alpha and gonadotropin-releasing hormone administration improve progesterone status, luteal number, and proportion of ovular and anovular dairy cows with corpora lutea before a timed artificial insemination program. J. Dairy Sci. 95:1831-1844.

Van der Maaten, M. J., and J. M. Miller. 1985. Ovarian lesions in heifers exposed to infectious bovine rhinotracheitis virus by non-genital routes on the day after breeding. Vet. Microbiol. 10:155-163.

Van der Maaten, M. J., J. M. Miller, and C. A. Whetstone. 1985. Ovarian lesions induced in heifers by intravenous inoculation with modified-live infectious bovine rhinotracheitis virus on the day after breeding. Am. J. Vet. Res. 46:1996-1999.

van Oirschot, J. T., C. J. Bruschke, and P. A. van Rijn. 1999. Vaccination of cattle against bovine viral diarrhoea. Vet. Microbiol. 64:169-183.

Walz, P. H., M. A. Edmondson, K. P. Riddell, T. D. Braden, J. A. Gard, J. Bayne, K. S. Joiner, P. K. Galik, S. Zuidhof, and M. D. Givens. 2015. Effect of vaccination with a multivalent modifiedlive viral vaccine on reproductive performance in synchronized beef heifers. Theriogenology 83:822-831.

Walz, P. H., M. D. Givens, A. Cochran, and C. B. Navarre. 2008. Effect of dexamethasone administration on bulls with a localized testicular infection with bovine viral diarrhea virus. Can. J. Vet. Res. 72:56-62.

Walz, P. H., D. L. Grooms, T. Passler, J. F. Ridpath, R. Tremblay, D. L. Step, R. J. Callan, and M. D. Givens. 2010. Control of bovine viral diarrhea virus in ruminants. J. Vet. Intern. Med. 24:476-486.

Wiltbank, M. C., A. H. Souza, P. D. Carvalho, R. W. Bender, and A. B. Nascimento. 2011. Improving fertility to timed artificial insemination by manipulation of circulating progesterone concentrations in lactating dairy cattle. Reprod. Fertil. Dev. 24:238-243. 